\title{
viewpoint
}

\section{Of maize and men}

\author{
Is the endorsement of GM crops science or politics? • by Stefan Flothmann \& Jan van Aken
}

'O utside the agricultural environment these genes are considered to be of no advantage, and thus, such hybrids will rapidly disappear once the crop is removed from the field' (Trewavas and Leaver, 2001).

'Regulatory agencies all over the world have permitted field trials for over 20 years now, so these things are there in the environment. If you're saying you can't have them, you're saying normal biological processes can't take place.' (Simon Barber of the biotech association Europabio, European Voice, 2001).

In the June 2001 issue of EMBO reports, Anthony Trewavas and Christopher Leaver asked whether opposition to GM crops is science or politics. For Greenpeace, as a political pressure group, the answer is clear: it is politics. For scientists such as Trewavas and Leaver, however, the question ought to be 'Is endorsement of GM crops science or politics?' The authors raise no doubt that, for them, the answer too is politics. By arguing that 40000 people are dying every day from malnutrition and leaving the reader with the impression that overcautiousness would be responsible for further suffering, they clearly make a political argument rather than a scientific approach to assess the safety of GM crops. Indeed, the authors fail to quote literature showing that sustainable agriculture projects in the Southern Hemisphere (Pretty and Hine, 2001) promise ways to increase food production whilst decreasing environmental impact and agroindustrial profits. By acknowledging that GM crops will not feed the world or eliminate poverty, Trewavas and Leaver's article raises the question: 'Is science politics?'

The political arguments opposing GM crops are manifold and range from corporate control versus food sovereignty, the freedom of choice when even organically grown food is threatened to be contaminated, the transparency and democratic level of decision making in genetic engineering politics and the preference of locally adapted developments over global 'one size fits all' solutions. But we will focus on some scientific aspects of the discussion. We believe that one aspect of sound science is an assessment of all available data. In their article, Trewavas and Leaver avoid mentioning scientific publications that question the safety of GM crops. Here, we will present some additional research in order to give a more complete overview of recent studies in biosafety research.

Genetic engineering is a completely different technique from traditional breeding, and as such, this could make transgenic crops a special threat to the
Secondly, the process of genetic engineering is neither targeted nor precise, but rather a crude intervention. As foreign genes are integrated with the plant genome in a random fashion, it is merely a matter of luck if the transgene is expressed as desired without inducing other changes in the plant's physiology or metabolism. Several mechanisms are known to influence the specific outcome of such a gene transfer and these cannot be anticipated. Also, foreign genes

Conventional breeding is not able to cross a bacterium with a plant

and therefore there has never been a crop with the Bt toxin gene to defend itself against predatory insects

environment. First, transgenic plants contain genes and traits that are completely new to the species and its environmental context. While traditional breeding can transfer genes only among related varieties or closely related species, genetic engineering allows for a movement of genes to radically different species. Conventional breeding is not able to cross a bacterium with a plant and therefore there has never been a crop with the Bacillus thuringiensis $(\mathrm{Bt})$ toxin gene to defend itself against predatory insects. Trewavas and Leaver are right in pointing out that the genes introduced through GM are not qualitatively different from those genes introduced by conventional breeding-insect resistance is indeed not new to maize. But they fail to realise that the very nature of the transgene may have important ecological repercussions. A conventional maize insect resistance genebe it a toxin, a feed deterrent or a structural component-evolved together with maize and its environment. In the process of co-evolution, these specific mechanisms of insect resistance adapted to the natural environment of maize, and vice versa. Bt toxin, on the other hand, was never part of the ecological and evolutionary context of maize plants. Thus, placing a novel potent toxin into a nonadapted environment is qualitatively different from moving genes within an existing gene pool based on co-evolution and adaptation. are regulated by their own promoters, thus bypassing the tight control system of the cell. Most scientists would agree that our understanding of the natural processes of recombination and the regulatory processes underlying conventional breeding techniques is still far from complete. It is therefore daring to assume that the particle gun is more accurate.

These two fundamental differences between conventional plant breeding and genetic engineering can have unforeseen consequences when transgenic plants are released into the environment. An array of risk scenarios has been discussed during the past decade. Some are rather hypothetical, while others have recently been shown to be closer to reality. The following three examples will highlight possible detrimental effects of transgenic plants on the environment.

Commercial enterprises have inserted herbicide, insect and virus resistance genes into important crops such as soybean, maize, rapeseed and wheat to confer a selective advantage to the plant in agricultural settings. These three traits provide for nearly $100 \%$ of all transgenic crops planted in 2000 (ISAAA, 2000). One likely threat that may result from resistance genes is the inadvertent and unwanted creation of plants with superior survival abilities against natural predators and human intervention. Often dubbed 'superweeds' in the public debate, such plants have an evolutionary advantage that would allow them to invade and/or take over entire ecosystems and drive out 


\section{viewpoint}

other species. Either the cultivated crop or sexually compatible relatives receiving the transgene could acquire (additional) weedy characteristics. The risk is greatest in areas where the crop plant originated because compatible plants-local varieties and landraces of the crop or wild species - will be abundant and facilitate the transfer of the foreign gene into the local plant population.

The major pathway of gene escape is via pollen transfer. Several studies have tried to determine the frequencies and distances of gene flow for several crop

Some scientists predict that volunteer canola could become one of Canada's most serious weed problems because of the large areas of the prairie provinces devoted to this crop

plants. The only consistent result of the experiments was that they are not consistent. In rapeseed, for example, outcrossing frequencies varied from $0.1 \%$ for a distance of $1 \mathrm{~m}$ (Pauk et al., 1995) to $1.2 \%$ at a distance of $1.5 \mathrm{~km}$ (Timmons et al., 1995). Indeed, a wealth of data has been produced on gene transfer during the past decade (Klinger et al., 1992; Manasse, 1992; Kareiva, 1994; Arriola and Ellstrand, 1996; Llewellyn and Fitt, 1996; Hokanson et al., 1997.) These studies measured actual pollination success and not-as suggested by Trewavas and Leaver-physical pollen distribution. It has been shown with a variety of different crops that experimental design and environmental parameters strongly influence outcrossing rates. Most scientists in this field therefore acknowledge that there is no 'safe' distance around a field of GM crops to prevent gene transfer from transgenic crops to other cultivated crops or wild relatives. Thus, the release of a transgenic plant into the environment will lead to an introduction of the transgene into the natural gene pool of this species.

For Central Europe, rapeseed and beet are of specific concern. Various forms of rapeseed grow in Europe, some of them are cultivated as crops, while others are regarded as 'weeds'. Spontaneous hybridisation between cultivated rapeseed and four wild-type relatives (Brassica rapa, $B$. juncea, B. adpressa and Raphanus raphanistra) has been reported (Eber et al., 1994; Mikkelsen et al., 1996), while introgression of a $B$. napus transgene into a weedy $B$. campestris population was also observed (Mikkelsen et al., 1996). Rapeseed is a persistent volunteer as the seed heads shatter easily and the seeds can remain dormant for a long period.

Herbicide-tolerant plants could also accumulate various genes to become multiresistant plants which will be as difficult to control as multi-resistant bacteria. The first rapeseed plants with a resistance to three herbicides-Monsanto's Roundup, Cyanamid's Pursuit and Aventis' Liberty-were identified in 1999 on a field in Alberta, Canada. The Royal Society of Canada warns that 'herbicide-resistant volunteer canola plants are beginning to develop into a major weed problem in some parts of the prairie provinces of Canada.' Indeed, some scientists predict that volunteer canola could become one of Canada's most serious weed problems because of the large areas of the prairie provinces devoted to this crop (Canadian Royal Society Expert Panel Report, 2001).

Experimental data on the potential invasiveness of transgenic plants are still limited. Trewavas and Leaver pointed out one study that suggested no additional invasiveness of transgenic plants in comparison with conventional varieties. However, another study provided preliminary evidence that insect

\section{The decline of specialised predators can lead to the emergence of secondary pests exploiting the now abundant food source after the target pest is eliminated}

flies fed on milkweed dusted with Bt pollen were severely affected in growth and development (Losey et al., 1999). Other nontarget species affected in controlled experiments include Coleomegilla maculata (Riddick and Barbosa, 1998), while Birch et al. (1999) showed the effect of snowdrop lectin on ladybirds. Data provided by the industry and published by the US-EPA also demonstrated a side-effect on collembola (EPA). It is likely that effects on other insect species would be revealed if the necessary experiments were undertaken.

But Trewavas and Leaver dismiss those non-target studies on the grounds that they were laboratory studies and worst case scenarios: 'just as an airline crash is the worst case scenario for flying'. Apart from the fact that planes actually do crash once in a while, the Losey study has been recently confirmed in field experiments, mimicking real world scenarios (Hansen and Obrycki, 2000). Furthermore, indirect effects were also reported. A field study of Bt potatoes showed a significant decline of a specialised ground beetle predator (Lebia grandis) after its primary prey species, the Colorado potato beetle, was eliminated. In the same study, the authors reported a significant increase in the number of leafhopper (Empoasca fabae) adults and nymphs in both the pure Bt potato fields and the mixed fields consisting of both GM and conventional potatoes (Riddick et al., 1998). The findings illustrate that the decline of specialised resistance indeed conters a selective advantage under environmental conditions as measured by an increased reproductive success of Bt rapeseed plants compared with non-transgenic varieties (Stewart, 1997).

Another potentially detrimental effect could come through the use of insect-resistance genes in GM crops. Bt toxin genes are currently the second most important commercial trait of transgenic crops and they pose a special threat to the insect population. A series of studies have now disproved the presumption that Bt crops harm only target pests. Lacewings-important beneficial insects - fed with corn borers raised on Bt maize suffered from increased mortality (Hilbeck et al., 1998), and monarch butter- predators can lead to the emergence of secondary pests exploiting the now abundant food source once the target pest is eliminated. The study further shows that farmers would still need insecticides to control secondary pests. Since the target pest is eliminated, it may seem that the decline of a specialised predator is ecologically irrelevant. But the long-term implications of an area-wide decline of such a predator for other cropping systems or natural habitats should not be dismissed easily.

It has been argued that the use of chemical insecticides would have a far more detrimental effect on the fauna. Apart from the fact that the maize corn borer was hardly ever controlled with synthetic insecticides, 


\section{viewpoint}

transgenic crops produce and expose the $\mathrm{Bt}$ toxin throughout the growing season in large quantities. Thus, the exposure of the insecticide to the local insect population is longer than when synthetic insecticides are used. Through the decrease of beneficial insects or indirect effects on predators synthetic herbicides. As the introduction of herbicide-tolerant crops has raised the question of whether they lead to an increase or a reduction of herbicide use, a wealth of data has been produced to support either view. Here, Trewavas and Leaver quote a study by Heimlich et al.

\section{Bt plants that expose insects to the toxin throughout the growing season are more likely to trigger resistance of the insect species}

higher up in the food chain, Bt crops can therefore affect whole ecosystems.

Furthermore, pests of all kinds have so far been able to withstand any human attempt to control them. By planting Bt crops and thus increasing the exposure of the pests to the toxin, the probability that insect species develop resistance against the toxin increases. Bt toxin is an ecologically-friendly pesticide and has been used with much success in organic agriculture. But Bt crops could soon render it useless, as the additional exposure may facilitate the rise and spread of resistance among insect pests. Since the traditional Bt spray is applied only a few times during a growing season and degrades rapidly within hours, the selective pressure to develop resistance is very low. Bt plants that expose insects to the toxin throughout the growing season are more likely to trigger resistance of the insect species.

It is hard to understand why proponents of GM crops disqualify risk assessment studies because they are laboratory studies. In fact, risk assessment of hazardous chemicals is based in large part on the concept of acute toxicity - the administration of high quantities of a substance to measure short-time effects and lethal doses. Carcinogenicity is not tested by real world scenarios - the administration of low doses over several decades-but for obvious reasons by short-term experiments using higher concentrations of the substances. However flawed this concept might be, it has helped to identify an array of hazardous substances, and no one would argue for the safety of benzene or other carcinogens on the grounds that their hazardous nature was only tested in worst case studies.

Herbicide-tolerance genes can have ecologically detrimental effects too. Indeed, any ecologically-friendly development in agriculture should aim at reducing - preferably to zero- the application of

(2000), published by the US Department of Agriculture, where a variety of data are presented, including an increase of 2.4 million pounds of active ingredients due to the adoption of herbicide-tolerant corn. However, the key problems in assessing the actual use of herbicides are the large differences between geographic regions, tillage systems and years. The most comprehensive approach to address these differences has been published recently by Benbrook (2001). His article provides a comprehensive review of the methodology used to assess the impact of transgenic plants on herbicide use. Based on the data provided by the US Department of Agriculture, Benbrook concluded

can neither be foreseen nor assessed before a release into the environment.

Of course, the specific risk of a transgenic plant differs, depending on the plant species, the nature of the transgene and the environmental context. Bt maize grown in Germany has little chance of outcrossing and becoming a 'superweed', but it has a large likelihood of harming indigenous insect species. In fact, current risk assessment procedures cannot estimate the true potential risk of a given transgenic plant. First, it is impossible to predict the unintended effects, as described above. Secondly, common risk assessment procedures, having been developed for toxic chemicals or nuclear power plants, are not applicable to transgenic organisms. Such procedures are based on a quantitative approach and an estimation of exposure rates. Transgenic plants, however, are self-replicating organisms that cannot be quantified for risk assessment purposes, because a single organism escaping from the target area can generate millions of new ones. In light of this inherent feature, and considering the manifold unknown risks, it is impossible to tag any transgenic plant as 'safe'.

\section{Common risk assessment procedures, having been developed for toxic chemicals or nuclear power plants, are not applicable to transgenic organisms}

that between $3.6 \%$ (in tillage production systems) and $7.1 \%$ (in no-till systems) more herbicide was used on Roundup Ready (RR) soybeans in the USA than on conventional varieties. In six states of the USA, over $30 \%$ more herbicides were applied on RR soybeans.

In addition to these concrete effectscreation of superweeds, non-target effects or increased herbicide use-unintended effects can cause unknown and unforeseeable changes in a plant's metabolism. Examples include the splitting of the stems and stunted growth of herbicidetolerant soybeans under high temperature conditions, or the change in wood colour in transgenic aspen with an altered lignin metabolism (Lapierre et al., 1999). Transgenic plants exhibiting obvious deviations are selected against prior to commercialisation, but many unintended effects will go unnoticed during the preliminary trials and may lead to detrimental effects that
The tremendous difficulties in controlling transgenic plants are highlighted by the recent StarLink scandal in the USA. StarLink is a Bt maize line that was registered only for animal feed use in the USA. However, in summer 2000, the first food products contaminated with StarLink maize appeared on the shelves in several countries. Even the 2001 seed stocks from several seed companies were found to be contaminated with StarLink. Aventis meanwhile acknowledges that the Cry9 gene of StarLink can no longer be recalled. This example emphasises that a commercial release of a transgenic plant will ultimately lead to a global spread of the transgene in food, feed and agriculture. StarLink must also be taken as a huge warning sign against the release of transgenic plants that produce bioactive compounds, such as pharmaceuticals. It would be a disaster if a potent heart drug or a blood-coagulating agent ends up in 


\section{viewpoint}

our cereals, as happened with StarLink maize.

Greenpeace therefore believes that transgenic crops pose some unique threats to the environment and human health, and calls for a ban on all releases of living GM

\section{The decision to take a risk must be based on the availability of strategies to avert major damage if something goes wrong}

organisms into the environment. There is no technical development without risks, and Greenpeace emphatically supports new technologies in many areas-which obviously all bear risks. As human beings, we are all subject to mistakes, so any new technology must allow for mistakes too. But the decision to take a risk must be based on the availability of strategies to avert major damage if something goes wrong.

The release of genetically engineered plants into the environment does not allow for mistakes. If such a plant turns out to have a disastrous effect, either on the environment or on human health, we have no measures at hand to deal with the problem. Once released into the environment, transgenic plants can never be recalled and they cannot be contained or confined. In the light of sustainable alternatives in agriculture, in the developed and developing world, should we really take this risk when there is no need?

\section{References}

Arriola, P.E.and Ellstrand, N.C. (1996) Crop-toweed gene flow in the genus Sorghum (Poaceae): spontaneous interspecific hybridization between johnsongrass, Sorghum halepense, and crop sorghum, S. bicolor. Am. J. Bot., 83, S1153S1160 (FROGMOPS No. 87).

Benbrook, C. (1999) Evidence of the magnitude and consequences of the Roundup Ready soybean yield drag from university-based varietal trials in 1998. Benbrook Consulting Services; Sandpoint, Idaho. See document at http://www.biotechinfo.net/RR_yield_drag_98.pdf

Benbrook, C.M. (2001) Troubled times amid commerical success for Roundup Ready soybeans. URL: http://www.biotech-info.net/ troubledtimes.html

Birch, A.N.E., Geoghegan, I.E., Majerus, M.E.N., McNicol, J.W., Hackett, C.A., Gatehouse, A.M.R. and Gatehouse, J.A. (1999) Tri- trophic interactions involving pest aphids, predatory 2-spot ladybirds and transgenic potatoes expressing snowdrop lectin for aphid resistance. Mol. Breeding, 5, 75-83.

Canadian Royal Society Expert Panel (2001) Elements of precaution: recommendations for the regulation of food biotechnology in Canada. An expert panel report on the future of food biotechnology prepared by the Royal Society of Canada at the request of Health Canada Canadian Food Inspection Agency and Environment Canada see: http://www.rsc.ca/ foodbiotechnology/GMreportEN.pdf.

Eber, F., Chèvre, A.M., Baranger, A., Vallée, P., Tanguy, X. and Renard, M. (1994) Spontaneous hybridization between a malesterile oilseed rape and two weeds. Theoret. Appl. Genet., 88, 362-368.

EPA MRID NO 434635, Bt maize (corn) leaf protein (LP176-0194) - 28 days survival and reproduction study in Collembola (Folsomia candidia).

Hansen, L.C. and Obrycki, J.J. (2000) Field deposition of Bt transgenic corn pollen: lethal effects on the monarch butterfly. Oecologia, 125, 241-248.

Heimlich, R.E., Fernandez-Cornejo, J., McBride, W., Klotz-Ingram, S.J. and Brooks, N. (2000) Genetically engineered crops: has adoption reduced presticide use? USDA Publication AER786. http/www.ers.usda.gov/epubs/pdf/aer786

Hilbeck, A., Moar, W.J., Pusztai-Carey, M., Filippini, A. and Zigler, F. (1998) Toxicity of Bacillus thuringiensis CrylAb Toxin to the predator Chrysoperla carnea (Neuroptera: Chrysopidae). Environ. Entomol., 27.

Hokanson, S.C., Grumet, R. and Hancock, J.F. (1997) Effect of border rows and trap/donor ratios on pollen-mediated gene movement. Ecol. Appl. 7, 1705-1710.

ISAAA (2000) Global review of commercialized transgenic crops: ISAAA briefs No. $21-2000$, at http://www.isaaa.org/briefs/Brief21.htm (as of February 1, 2001).

Kareiva, P., Morris, W. and Jacobi, C.M. (1994) Studying and managing the risk of cross fertilization between transgenic crops and wild relatives. Mol. Ecol., 3, S15-S21.

Klinger, T., Arriola, P.E. and Ellstrand, N.C. (1992) Crop-weed hybridization in radish (Raphanus sativus): effects of distance and population size. Am. J. Bot., 79, S1431-S1435.

Lapierre, C. et al. (1999) Structural alterations of lignins in transgenic poplars with depressed cinnamyl alcohol dehydrogenase or caffeic acid $O$-methyltransferase activity have an opposite impact on the efficiency of industrial kraft pulping. Plant Physiol., 119, 153-163.

Llewellyn, D. and Fitt, G. (1996) Pollen dispersal from two field trials of transgenic cotton in the Namoi Valley, Australia. Mol. Breeding, 2, S157-S166.

Losey, J.E., Rayor, L. and Carter, M.E. (1999) Transgenic pollen harms monarch larvae. Nature, 399, 214.

Manasse, R.S. (1992) Ecological risks of transgenic plants: effects of spatial dispersion on gene flow. Ecol. Appl., 2, S431-S438.

Mikkelsen, T.R., Andersen, B. and Jörgensen, R.B. (1996) The risk of crop transgene spread. Nature, 380, 31.
Pauk, J., Stefanov, I., Fekete, S., Bögre, L., Karsai, I., Feher, A. and Dudits, D. (1995) A study of different (CaMV 35S and mas) promoter activities and risk assessment of field use in transgenic rapeseed plants. Euphytica, 85, S411-S416.

Pretty, J. and Hine, R. (2001) Reducing food poverty with sustainable agriculture: a summary of new evidence. Final report from the SAFE-World Research Project, February, 2001. University of Essex, Colchester. http://www2.essex.ac.uk/ces/ ResearchProgrammes/CESOccasionalPapers/ SAFErepSUBHEADS.htm

Riddick, E.W. and Barbosa, P. (1998) Impact of Cry3A-intoxicated Leptinotarsa decemlineata (Coleoptera: Chrysomelidae) and pollen on consumption, development, and fecundity of Coleomegilla maculata (Coleopter: Coccinellidae). Ann. Entomol. Soc. Am., 91, 303-307.

Riddick, E.W., Dively, G. and Barbosa, P. (1998) Effect of a seed-mix deployment of Cry3Atransgenic and non-transgenic potato on the abundance of Lebia grandis (Coleoptera: Carabidae) and Coleomegilla maculata (Coleoptera: Coccinellidae). Ann. Entomol. Soc. Am., 91, 647-653. Reviewed in Hilbeck, A., Meier, M.S. and Raps, A. (2000) Review on nontarget organisms and Bt plants. Report to Greenpeace International, Amsterdam, April 2000, EcoStrat GmbH, Zürich, Switzerland.

Smeda, R.J., Allen, J.A. and Johnson, W.G. (1998) Herbicide resistant weed update for Missouri. University of Missouri-Columbia, at http:// www.psu.missouri.edu/agronx/weeds/ newsletterarticles/98agchemshcourse.html

Stewart, C.N. (1997) Transgenic insecticidal oilseed rape on the loose. Proceedings of the Workshop 'Commercialisation of Transgenic Crops', Canberra, Australia March 11-13, 1997.

Trewavas, A. and Leaver, C. (2001) Is opposition to GM crops science or politics? An investigation into the arguments that GM crops pose a particular threat to the environment. EMBO Rep., 2, 455-459.

Timmons, A.M., O’Brien, E.T., Charters, Y.M., Dubbels, S.J. and Wilkinson, M.J. (1995) Assessing the risks of wind pollination from fields of genetically modified Brassica napus ssp. oleifera. Euphytica, 85, S417-S423.
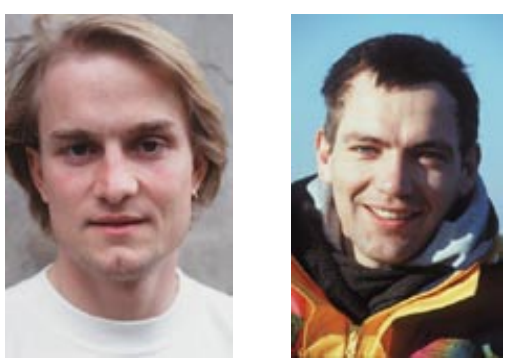

Stefan Flothmann and Jan van Aken are at Greenpeace, Germany.

E-mail: stefan.flothmann@greenpeace.de

DOI: 10.1093/embo-reports/kve166 